\title{
La estabilidad ocupacional reforzada de las personas en situación de discapacidad en Colombia
}

\author{
The reinforced labor stability of people in a situation \\ of disability
}

\section{Estabilidade laboral reforçada das pessoas com deficiência na Colômbia}

\section{La stabilité professionnelle renforcée des personnes en situation de handicap en Colombie}

\author{
Wilson Yesid Suarez Manrique (iD) \\ Doctor en Derecho y Gobernanza \\ Corporación Universitaria Rafael Núñez campus, Cartagena - Colombia \\ Correo electrónico: wilson.suarez@curnvirtual.edu.co
}

\section{Georgina Isabel de León Vargas}

Magister en Derecho Laboral

Integrante colíder del Grupo de investigación Derecho Público del Programa de Derecho de la Corporación Universitaria Rafael Núñez campus, Cartagena - Colombia Correo electrónico: georgina.deleon@curnvirtual.edu.co 


\section{Resumen}

El artículo analiza el problema de los sujetos del derecho fundamental a la estabilidad laboral reforzada en la jurisprudencia de la Corte Constitucional. Este problema refiere a la titularidad del derecho y a su destinatario. En cuanto a la titularidad del derecho, el análisis propone el criterio del empleador hipotético como sustituto del criterio del trabajador vulnerable. Y en relación con el destinatario, se plantea la regla de la responsabilidad como sustituta de la regla de la no responsabilidad.

\section{Palabras clave}

Estabilidad laboral reforzada, protección deficiente, empleador hipotético, regla de responsabilidad.

\section{Abstract:}

This paper analyses the problem of the subjects of the fundamental right to reinforced labor stability in the case-law of the Corte Constitucional. This problem relates to the ownership of the right and its recipient. As for the right's ownership, it proposes the hypothetical employer criteria as a substitute for the vulnerable worker criteria. And in relation to the recipient, it considers the rule of responsibility as a substitute for the rule of non-responsibility.

\section{Key Words:}

Reinforced labor stability; deficient protection; hypothetical employer; rule of responsibility.

\section{Resumo}

Esse artigo analisa o problema dos sujeitos do direito fundamental à estabilidade laboral reforçada na jurisprudência do Tribunal Constitucional. Esse problema se refere à titularidade do direito e seu destinatário. No tocante à titularidade do direito, a análise propõe o critério do empregador hipotético como substituto do critério do trabalhador vulnerável. No que diz respeito ao destinatário, estabelece-se a regra de responsabilidade como substituta da regra da não responsabilidade.

\section{Cómo citar este artículo:}

Suarez, W. Y. \& De León, G. I. (2019). La estabilidad ocupacional reforzada de las personas en situación de discapacidad en Colombia. Revista de la Facultad de Derecho y Ciencias Políticas, 49 (131), pp. 361-385. doi: http://dx.doi.org/10.18566/rfdcp.v49n131.a06

Recibido: 27 de agosto de 2018.

Aprobado: 31 de julio de 2019. 


\section{Palabras clave}

estabilidade laboral reforçada, proteção deficiente, empregador hipotético, regra de responsabilidade.

\section{Résumé}

Larticle analyse le problème des sujets du droit fondamental à la stabilité professionnelle renforcée dans la jurisprudence de la Cour Constitutionnelle. Ce problème concerne la titularité du droit et son destinataire. Concernant la titularité du droit, l'analyse propose le critère de l'employeur hypothétique comme substitut du critère du travailleur vulnérable. Quant au destinataire, la règle de la responsabilité est proposée en remplacement de la règle de non-responsabilité.

\section{Mots clés}

Stabilité professionnelle renforcée, protection insuffisante, employeur hypothétique, règle de responsabilité

\section{Introducción}

En su afamado libro Virtud soberana, (Dworkin, 2003, pág. 28) este autor norteamericano recuerda el relato de la cigarra y la hormiga. Para Dworkin, los políticos, en ocasiones, tienen que quitarles la comida constantemente a las "hormigas" para dárselo a las cigarras, situación que genera, como es de esperarse, notorio descontento. La noción de justicia distributiva (Vigo, 2003, pág. 80)(Vigo, 2003) parece estar en contra de esta situación, pues la correcta repartición de los bienes sociales requiere una justificación adecuada.

En la Sentencia T -025 de 2011, la Corte Constitucional colombiana ratificó la postura que había venido sosteniendo desde hace varios años. Según esta sentencia, las personas en situación de discapacidad gozan de un derecho de estabilidad laboral reforzada, que exige que se deben suplir requerimientos especiales para ser desvinculados del contrato de trabajo. De forma explícita ha manifestado que las personas en situación de discapacidad, "gozan de un derecho fundamental a la estabilidad laboral reforzada, lo que implica que no pueden ser desvinculadas de su empleo sin autorización previa de la autoridad administrativa o judicial competente" (Corte Suprema de Justicia).

la Corte radica la fundamentación de este derecho, desde el enfoque constitucional, en los artículos 13, 16, 47, 48 y 53 de la Constitución Política 
de Colombia. Y, desde lo legal, en la Ley 361 de 1997, mediante la cual se establecen los mecanismos de integración social de las personas en situación de discapacidad.

La Sala Laboral de la Corte Suprema de Justicia también ha discutido el tópico de la estabilidad laboral de las personas en situación de discapacidad, empero, ha tenido una visión reducida de la titularidad y de los destinatarios de estos derechos, pues esta entidad ha estado sujeta a las previsiones normativas establecidas en la Ley 361 de 1997 donde consta que, únicamente, deben protegerse las limitaciones calificadas como moderadas, severas y profundas; un ejemplo de esta posición puede verse en las sentencias SL-1360 y SL-5103 de 2018 y , en donde se ha interpretado de forma restrictiva la Sentencia C-531 de 2000de la Corte Constitucional.

Ahora bien, recientemente, la Corte Suprema de Justicia, en la Sentencia SL-1360 de 2018, abandona el criterio sentado en la Sentencia CSJ SL-36115, del 16 marzo de 2010, reiterada en la Sentencia SL-35794, del 10 de agosto de 2010, y "en su lugar, se postula que el despido de un trabajador en estado de discapacidad se presume discriminatorio, a menos que el empleador demuestre en juicio la ocurrencia real de la causa alegada”.

La postura de la Corte Suprema de Justicia no resulta tan problemática como la de la Corte Constitucional, en lo que concierne a los titulares del derecho glosado, pues su visión reducida y legalista, fincada en el Artículo 5 de la Ley 361 de 1997, no ostenta una indeterminación normativa tan alta como la que se deriva de la doctrina constitucional. Por lo cual, no será objeto de estudio en este artículo.

En cambio, la visión ampliada de la Corte Constitucional sobre este derecho ha generado importantes incongruencias y aporías, pues la reconstrucción del derecho a la estabilidad laboral reforzada ha sido fundada por la Corte dentro de una interpretación plausible derivada de los campos de indeterminación semántica de los postulados constitucionales referidos.

Esta reconstrucción de la Corte Constitucional, desde un punto de vista estructural, presenta dos problemas generales, los cuales persisten a pesar de lo descrito en la sentencia SU-049 de 2017, por cuanto los supuestos normativos contienen expresiones con textura abierta. El uno alude a que no está claro quiénes son los titulares del derecho, lo que es problemático a la hora de revisar su determinación en casos marginales, lo cual implica dispersión e 
indeterminación jurídicas. El otro refiere a que el destinatario de este derecho ha sido analizado de forma sesgada, sin tener en cuenta la complejidad del derecho y las diferentes facetas prestacionales que representa.

Entonces, el objetivo del presente artículo es analizar en la jurisprudencia de la Corte Constitucional de Colombia el problema de la estructura del derecho fundamental a la estabilidad laboral reforzada de las personas en situación de discapacidad, especialmente en cuanto a la titularidad del derecho y a su destinatario. Para cumplir con lo anterior, el escrito se divide en tres partes. En la primera se reconstruye la doctrina de la estabilidad laboral reforzada de la Corte, en cuanto a su fundamentación, al concepto de discapacidad y a las subreglas de protección. Esta parte presenta el soporte conceptual que limita el objeto de estudio del artículo. En la segunda se exponen las principales objeciones a la titularidad del derecho y al destinatario predilecto. El objeto de esta sección es evidenciar los problemas estructurales que presenta la reconstrucción del derecho realizada por la Corte. En la tercera sección se plantea la figura del empleador hipotético como remplazo del criterio del trabajador vulnerable, y la regla de responsabilidad del trabajador como sustituta de la regla de la no responsabilidad.

\section{La doctrina de la estabilidad laboral reforzada de las personas en situación de discapacidad}

Dentro de las facultades de dirección de una empresa se encuentra la del despido. Este es una pieza central de la regulación laboral. Para (Gorelli, 2010, págs. 90,91,92) es "indudable que el despido es una de las instituciones jurídico- laborales esenciales dentro del derecho del trabajo; más aún, la regulación sobre despido es uno de los ejes fundamentales sobre los que gira el ordenamiento jurídico laboral”.

El despido es considerado un acto de violencia privada, una incultura jurídica (Baylos, 2009, pág. 120). Como acto de violencia debe ser regulado y limitado por los derechos fundamentales (Hernández, 1997, pág. 25). La Corte Constitucional colombiana, como alternativa para proteger a las personas más débiles de los abusos del empleador, ha reconstruido la figura de la estabilidad laboral reforzada de las personas en situación de discapacidad. Entre otras 
cosas, por cuanto las personas en situación de discapacidad, desde la fundación del derecho privado, han gozado de una protección deficiente (Claro, 1978, pág. 20).

\subsection{El fundamento de la estabilidad laboral reforzada, la noción de discapacidad, los sujetos y las reglas de protección de la Corte Constitucional}

La Corte ha radicado el fundamento de esta doctrina, por lo general, en argumentos de autoridad y de derecho comparado. En cuanto a los argumentos de autoridad, la Corte se ha basado en la concepción del Estado Social de Derecho, en la igualdad material, en la solidaridad, en el Artículo 47 del Texto Constitucional y en el desarrollo legislativo. Según la concepción del Estado Social de Derecho, al Estado le corresponde adelantar acciones para lograr la procura existencial de las personas (Forsthoff, 1986). De conformidad con la interpretación del Artículo 13 de la CP (especialmente en lo que refiere al inciso segundo), se ha entendido que las personas en situación de discapacidad se encuentran en una especial condición de debilidad, por lo que se hace necesario tomar medidas fácticas y jurídicas para buscar una igualdad real (Bernal, 2005, pág. 19). Según el Artículo 47 de la Carta Magna, las personas con discapacidad gozan de una especial protección.

En desarrollo del mandato Constitucional anterior, el legislador expidió la Ley 361 de 1997, mediante la cual se establecen mecanismos de integración social de las personas con limitaciones. El Artículo 26 de la norma en comento regula la estabilidad laboral reforzada en personas en situación de discapacidad. En esta disposición se instaura la prohibición al empleador de despedir o terminar los contratos de trabajo en razón de la limitación que sufra el trabajador, salvo que medie autorización de la oficina del trabajo. Para la Corte, en la Sentencia T- 081 de 2013, "según la literalidad de la disposición, quienes procedan en forma contraria a ella, estarán obligados al pago de una indemnización equivalente a ciento ochenta días de salario”.

Los argumentos de derecho comparado se basan en referencias que efectúa la Corte a los instrumentos universales y latinoamericanos de protección a la discapacidad, en las que se destacan la Declaración Universal de los Derechos Humanos, el Pacto Internacional de Derechos Económicos, 
Sociales y Culturales, la Convención sobre los Derechos de las Personas con Discapacidad y su protocolo facultativo (aprobados el 13 de diciembre de 2006 en Nueva York), la Declaración de los Derechos de las Personas con Retardo Mental, la Declaración de los Derechos de los Impedidos, la Declaración de las Personas Sordo- Ciegas, el Programa de Acción Mundial para las Personas con Discapacidad, y normas uniformes para la igualdad de oportunidades para personas con discapacidad. Mediante estos acuerdos, además de fundamentar la adscripción (Bernal C. M., 2003, pág. 28) del derecho a la estabilidad laboral reforzada, ha sido posible fincar su alcance y orientar la protección.

Para analizar el significado que la Corte le ha dado a la noción de discapacidad, el punto de partida es el concepto "persona en situación de discapacidad”. El entendimiento de la idea de discapacidad se ve afectado por múltiples problemas de ambigüedad. En primer lugar, según Bernal, (Bernal C. M., 2003, pág. 17), hay una dicotomía para el uso de concepciones distintas para las áreas de la medicina, la psicología y el derecho. Ambigüedad que se ve agravada por el uso disímil y polifónico que han hecho las leyes y la jurisprudencia al respecto (Vila, 2011, pág. 14).

La concepción de discapacidad ha tenido, en la Corte, distintos alcances: en un principio se partió de una noción limitada acerca de la discapacidad y, posteriormente, fue ampliada hasta llegar a referir elementos muy generales y ambiguos. De dicha doctrina pueden extraerse tres etapas generales de la noción de discapacidad: una reducida, referida a las personas con discapacidad severa; otra moderada; y una última ampliada. La que se enuncia por último se pondera impropia, y se refiere a los trabajadores que han sido afectados en los aspectos centrales de su desarrollo vital (se dice "impropia” en el sentido de que no refleja la situación de lo que, "en general”, describe a una persona en situación de discapacidad, o bien ha sido remplazada por la de debilidad manifiesta) en el entendido de que la protección no se aplica solo a las personas en situación de discapacidad, sino que se transfiere a quienes hacen parte de la categoría "personas en debilidad manifiesta”..

La Corte Constitucional de Colombia, en la Sentencia C-824 de 2011 señaló que no solo las personas con discapacidad severa son destinatarias de la protección de la estabilidad laboral reforzada y de las demás prestaciones establecidas en la Ley 361 de 1997. Incluyó también, como beneficiarios de dicha protección, a los individuos con una limitación leve y moderada, de modo que: 
La referencia específica que hace el Artículo 1. De la Ley 361 de 1997, a las personas con limitaciones "severas y profundas" no puede tomarse como expresiones excluyentes (SIC) para todos los artículos que conforman la citada ley. En punto a este tema, es de aclarar que la clasificación del grado de severidad de una limitación (Art. 7. º , Ley 361 de 1997) no implica la negación y vulneración de un derecho (Congreso, 1997).

La ampliación de la noción por parte de la Corte la ha llevado a cambiar su objeto originario de proteger a las personas en situación de discapacidad para salvaguardar a quienes se encuentren en condiciones de debilidad manifiesta 0 en situación de vulnerabilidad, con lo cual, sin entrar al debate que ello genera, se igualan las dos nociones. En la sentencia glosada, sostuvo:

Más que de discapacidad leve y moderada, la jurisprudencia ha señalado que en estas situaciones debe hablarse de personas que, por su estado de salud física o mental, se encuentran en condiciones de debilidad manifiesta, que les dificulta trabajar en ciertas actividades o hacerlo con algunas limitaciones y que, por tanto, requieren de una asistencia y protección especial (SIC) para permitirle su integración social y su realización personal, además de que gozan de una estabilidad laboral reforzada (Congreso, 1997).

El planteamiento que hace la Corte sobre las personas en condición de debilidad manifiesta exigencias epistemológicas y prácticas bastante fuertes. El concepto que ha dado esta institución se ha dilatado, pues al fijar criterios generales les exige a los jueces calificar con amplios costados de discreción las cualidades y calidades de los individuos.

Según la Corte, en la Sentencia T-018 de 2013:

El juez (...) para identificar la titularidad del derecho a la estabilidad laboral en las personas discapacitadas y estudiar la procedencia del amparo, debe evaluar los factores de vulnerabilidad que se manifiestan en motivos de salud, o por cualquier circunstancia que afecte al actor en su bienestar físico, mental o fisiológico.

El cuestionamiento sobre lo que significa "cualquier circunstancia” queda latente, y de igual forma, el cómo los jueces pueden lograr la calificación de los individuos, sin tener los conocimientos de siquiatría, sicología o medicina. 
En cuanto a los sujetos y las reglas de protección, la Corte Constitucional ha tomado una posición bastante heterodoxa y clásica sobre la forma como debe resguardar la estabilidad laboral reforzada. En relación con los titulares del derecho, este organismo ha tomado una concepción muy general; ha ampliado el concepto de discapacidad y lo ha llevado al de personas en debilidad manifiesta o vulnerabilidad. Luego, los titulares del derecho a la estabilidad laboral reforzada, según la Corte, serían todas aquellas personas que presenten una afectación en sus capacidades intelectuales, físicas, mentales y sociales. De forma literal ha expresado que el estado de vulnerabilidad "se manifiesta a través de factores que afectan su salud, bienestar físico, mental o fisiológico” (Corte Constitucional, 2013).

La Corte Constitucional les ha dado una amplia facultad a los jueces para que cataloguen la titularidad del derecho de conformidad con las directrices generales que ha emitido.

En relación con el destinatario del derecho, la Corte ha aplicado casi exclusivamente la concepción de que es el empleador quien debe responder por las exigencias derivadas de la estabilidad reforzada. Esto, por cuanto, en algunos casos, quien contrata debe costear los salarios y cargas de seguridad social del trabajador y, de esta manera, no puede despedirlo o debe reubicarlo en tareas que pueda desarrollar. Luego, esto implica que ha pasado por alto la posibilidad de que el Estado, el propio trabajador o sus familiares deban asumir responsabilidades.

Con respecto a las reglas de protección de la Corte, pueden señalarse unas pautas generales sobre la estabilidad laboral reforzada, y unas específicas sobre los contratos a término fijo. En el primer caso, esta entidad representativa ha utilizado "reglas de protección” anteriores y posteriores. Ha hecho especial énfasis en que todo despido de un trabajador con discapacidad debe contar con la autorización previa de la autoridad de trabajo correspondiente. La consecuencia de que este requisito no se tenga presente es que la terminación del contrato laboral será ineficaz. Como consecuencia de dicha ineficacia, el empleador deberá reintegrar al empleado y pagarle una indemnización de 180 días de salario. El precedente ha indicado que la liquidación de la compensación no otorga eficacia al despido, en la medida en que no protege el derecho a la estabilidad laboral reforzada de las personas discapacitadas. De hecho, las salas de revisión han subrayado que "ninguna actuación del empleador torna en eficaz el despido de un trabajador en situación de discapacidad si no existe autorización de la autoridad competente. 
Por otra parte, el inspector de trabajo tiene el deber de autorizar o no el despido del trabajador; se trata de una intervención externa a la relación laboral que debe analizar si se dan las causas justas alegadas por el empleador, o si se trata de una situación discriminatoria en razón a la discapacidad del trabajador. La Corte ha enfatizado en la seriedad de la función del inspector, en el entendido de que no se trate del cumplimiento de un formalismo, sino en un verdadero análisis de fondo sobre la ocurrencia de la causal o las causales alegadas. Para la Corte Constitucional de Colombia, en la Sentencia C-531 de 2000,

(El) permiso no es una mera formalidad, puesto que se estableció con el fin de que la autoridad administrativa respectiva verifique que el empleador, al despedir a un trabajador con discapacidad, no está vulnerando los derechos de una persona que cuenta con especial protección constitucional.

El resultado de pasar por alto la intervención adecuada del inspector es, según la Corte, dejar sin sustancia el contenido de la estabilidad laboral reforzada. "Omitir dicho deber vacía el contenido del derecho a la estabilidad laboral reforzada y aumenta el estado de vulnerabilidad en el que se encuentran los trabajadores disminuidos” (Corte Constitucional S. T.-4., 2013). Así las cosas, según la Sentencia T-447 de 2013:

(i) No procede el despido de una persona en situación de discapacidad sin que exista autorización del Ministerio de Trabajo, (ii) cuando el empleador alega justa causa, el Ministerio debe verificar si la causal alegada es justa o no, esto, con la finalidad de proteger al trabajador que se encuentra en situación de discapacidad, (iii) el Ministerio no puede evadir su responsabilidad refugiándose en una presunta justa causa y (iv) aun existiendo indemnización, no procede el despido sin previa autorización.

Como forma de acentuar la protección en estos casos, la Corte Constitucional colombiana ha creado una presunción jurídica de discriminación. Según esta, el despido que recae sobre un trabajador en condiciones de vulnerabilidad implica la presunción de despido sin justa causa que invierte la carga de la prueba, por lo cual, el empleador debe probar los argumentos razonables de su decisión, es decir, que el despido no se debió a la condición de discapacidad. A tenor literal, en Sentencia T- 225 de 2012, la Corte ha señalado que:

La jurisprudencia constitucional ha presumido que, cuando un empleador despida sin justa causa y sin permiso del Ministerio de la Protección Social a un trabajador en condiciones de debilidad manifiesta, el motivo del despido 
fue tal situación. Dicha presunción revierte la carga de la prueba y obliga al empleador a justificar la causa de la desvinculación en una razón objetiva diferente al vencimiento del plazo y la situación de debilidad.

En cuanto a las reglas de protección posteriores, se ha puesto el enfoque especialmente en cuatro situaciones, mediante las cuales se protege reforzadamente al trabajador: la ineficacia del despido, la readmisión del trabajador, la capacitación y el pago de indemnizaciones. Se trata de escenarios jurídicos que tienen que darse para la efectiva protección, en el entendido de extraer de la vida jurídica los efectos del despido, restaurar la relación rota, buscar la forma de integrar al trabajador al mundo laboral, y castigar al empleador por su despido ilegal. Para la Corte, en Sentencia T- 547 de 2013:

El juez que conozca del asunto tiene el deber prima facie de reconocer a favor del trabajador: en primer lugar, la ineficacia de la terminación o del despido laboral; en segundo lugar, el derecho a ser reintegrado a un cargo que ofrezca condiciones iguales o mejores que las del cargo desempeñado hasta su desvinculación; en tercer lugar, el derecho a recibir capacitación para cumplir con las tareas de su nuevo cargo, si es el caso (Art. 54, C.P.); y en cuarto lugar, el derecho a recibir una indemnización equivalente a ciento ochenta días del salario.

De lo anterior, la Corte concluye que la autonomía empresarial (Valverde, 1999) se restringe y debe atenerse a las cargas solidarias que la Constitución le impone ${ }^{1}$. Esta carga es la de garantizar la permanencia del trabajador en el empleo. No obstante, este organismo legal no va tan lejos y asimila la carga con la inamovilidad del trabajador ${ }^{2}$. Es decir, establece unas limitaciones al deber de solidaridad que no son del todo claras. Estas cargas impuestas al empleador, según al Corte, deben limitarse teniendo en cuenta, como siempre,

1 La Corte Constitucional, en la Sentencia T-226 de 2012, indica que: "Si bien en el ejercicio de la voluntad de las partes y el desarrollo de la actividad empresarial los patronos pueden optar por la modalidad contractual de limitar por tiempo definido sus contratos y someterlos al cumplimiento de la labor u obra, esta facultad se ve delimitada por normas constitucionales que tutelan el derecho constitucional a la estabilidad laboral reforzada, para aquellos grupos de especiales condiciones".

2 Según la Corte Constitucional, en la Sentencia T-225 de 2012, la estabilidad "no supone que el trabajador sea inamovible, pues una vez se presenten causales objetivas (situaciones de indisciplina, ineficiencia y bajo rendimiento) que autorizan a la terminación unilateral del contrato de trabajo, deben ser observadas las reglas propias del debido proceso que son exigibles a los particulares, garantizándose concretamente el derecho a la defensa, que exige del empleador informar los motivos que originaron el despido y reconoce al trabajador la posibilidad de controvertir las razones aludidas. Pero, en todo caso, si el trabajador se encuentra en una situación de protección especial, debe mediar autorización de la autoridad del trabajo so pena de la ineficacia de tal despido". 
las circunstancias del caso en concreto y, especialmente, las de naturaleza subjetiva que le impidan al empleador su ejecución, y la inexistencia de derechos absolutos. De forma expresa, así lo señala en la Sentencia T- 226 de 2012:

Este deber de solidaridad del empleador se puede ver afectado en la medida en que no tenga la capacidad de hacerlo, le sea imposible o le afecte el desarrollo normal de la actividad, situación que también debe ser demostrada. En efecto, la protección constitucional frente a esta clase de personas no implica per se el ejercicio de derechos absolutos o a perpetuidad, ya que no existe el derecho fundamental a la conservación del trabajo. La especial protección constitucional de las personas en estado de debilidad manifiesta exige del juez de tutela el análisis de cada uno de los requisitos y presupuestos al momento de determinar si procede o no el reintegro.

\section{Las objeciones a la protección}

La reconstrucción efectuada por la Corte Constitucional de Colombia es muy amplia e imprecisa en diversos aspectos. Dicho estatus imposibilita una cartografía precisa, pero no impide mostrar claramente sus ideas representativas. Esta amplitud le ha acarreado múltiples inconvenientes. Las construcciones elaboradas han sido presa de múltiples errores que han llevado a contradicciones (Ugarte, 2011, pág. 34). Las principales críticas a la doctrina de la Corte pueden agruparse en dos categorías: los sujetos y el contenido.

\subsection{Las aporías de la titularidad y la aporía de los destinatarios}

En el primer evento, el relativo a la categoría de los sujetos, cabe preguntarse: ¿existe claridad acerca de cuáles son las personas que reciben la protección? La Corte Constitucional, al ampliar la concepción de personas en situación de discapacidad y llevarla a un nivel tan general, el de personas en situación de vulnerabilidad, ha creado una situación que, en principio, puede valorarse positivamente. Por ejemplo, en la Sentencia T-1040 de 2001, los trabajadores con discapacidad severa eran los principales beneficiarios de esta protección. Sin embargo, la Corte entendió que existían otros grupos de personas que 
se hacía necesario proteger, como era el caso de aquellos quienes, por sus limitaciones física, intelectual o social, no podían seguir desarrollando sus actividades en condiciones regulares.

La Corte ha establecido el criterio según el cual se predica el derecho a la estabilidad ocupacional reforzada a las personas que presenten una situación de salud que les impida o dificulte sustancialmente el desempeño de sus labores en condiciones regulares. Es así como en las sentencias C-458 de 2015 o en la SU- 040 de 2018, la Corte

Ha amparado el derecho a la estabilidad ocupacional reforzada de quienes han sido desvinculados sin autorización de la Oficina del Trabajo, aun cuando no presenten una situación de pérdida de capacidad laboral moderada, severa o profunda, ni cuenten con certificación que acredite el porcentaje en el que han perdido su fuerza laboral, si se evidencia una situación de salud que les impida o dificulte sustancialmente el desempeño de sus labores en condiciones regulares (Corte Constitucional s. C.-4., 2015).

Sin embargo, esta situación resulta indeseable por la amplitud y la falta de claridad conceptual (Suàrez, 2012, pág. 13), lo cual, como se indica a continuación, conlleva a la presentación de múltiples problemas. Así las cosas, los criterios que ha utilizado la Corte para establecer la titularidad del derecho, en lugar de mejorar la protección, la han debilitado. La estabilidad laboral reforzada ha sido utilizada como un cajón de sastre (Posner, 2011, pág. 46), como un comodín, que se usa por cualquier empleado sin tener en cuenta sus especiales situaciones. ¿Qué trabajador no puede argumentar que la pérdida del empleo le genera una situación de vulnerabilidad o que se encuentra inmerso en ella? El modelo del asalariado actual es el del trabajador perfectible, lo que implica necesariamente las deficiencias intelectuales, fiscas o culturales referidas.

Como la Corte se ha basado en supuestos muy generales, que pueden valorarse de manera muy subjetiva por los involucrados, y la situación de vulnerabilidad es una circunstancia, en muchos casos, de gran contenido de relatividad, los principales problemas referidos a la falta de claridad conceptual a los que no hace frente de manera adecuada la titularidad del derecho creado por la Corte son los siguientes: primero, no existen criterios más o menos claros para determinar el titular del derecho, máxime cuando la Corte Constitucional ha ampliado los potenciales beneficiarios y ha otorgado amplias facultades de discrecionalidad a los jueces. Segundo, los elementos de 
análisis para determinar la vulnerabilidad abarcan un sinfín de posibilidades sobre las cuales el juez no tiene un conocimiento adecuado. Existe una incompetencia epistemológica (Petev, 1996, pág. 69) para determinar el grado de la vulnerabilidad de los trabajadores.

Tercero, entre más se amplía un derecho de defensa o prestacional, en cuanto a sus titulares, menor puede protegerse como una situación excepcional (Paine, 1984, pág. 39), al afectar a muchos trabajadores, la protección se ve directamente afectada. Cuando la titularidad de los derechos es amplia y los recursos son escasos (Calabresi, 1992, pág. 123) ello produce la insatisfacción de todas las necesidades o su parcial cubrimiento de manera adecuada, teniendo en cuenta una perspectiva prioritaria. El hecho de que sean muchos los titulares del derecho conlleva a que no se les pueda prestar la misma vigilancia y control (Burgoa, 1954, pág. 35). La extensión de los criterios de forma tan amplia para identificar a los titulares del derecho ha comportado, inexorablemente, la desprotección del mismo. Lo más positivo de este "adelanto" de la Corte ha sido la formalización de los requisitos, establecida en la Sentencia T-447 de 2013. Sin embargo, en su afán de proteger a los vulnerables ha terminado rezagando sus condiciones. No existe una estabilidad reforzada cuando el derecho resulta potencialmente igual para toda clase de trabajadores.

Ahora bien, en el segundo evento, relativo a los destinatarios de las obligaciones, se hace necesario tener en cuenta que la Corte Constitucional ha concebido, como principal obligado, al empleador, bajo el entendido del principio de solidaridad y que es él quien se beneficia por la labor adelantada por el trabajador. En principio parece razonable pensar, que quien ha contratado al trabajador y se ha beneficiado de sus labores personales, es quien deba responder, primeramente.

El hecho de que la Corte establezca como principal obligado de la prestación al empleador, salvo en situaciones excepcionales donde puede eximirse, muestra un análisis sesgado de la forma como debe obrar la protección en el empleo. La estabilidad laboral reforzada no puede ser, por entero, una obligación a cargo del empleador, pues necesita complementarse con el compromiso del trabajador y del Estado. Los principales problemas que presenta la elaboración de la doctrina de la Corte sobre este punto son, en este sentido, tres: problemas de fundamentación, de enfoque y de proporcionalidad. 
El fundamento de la obligación impuesta al empleador ha estado en el principio de solidaridad, La Corte Constitucional, en la Sentencia T-445 de 2014 estableció lo siguiente:

De acuerdo con la jurisprudencia anteriormente reseñada, el principio de solidaridad tiene tres (3) manifestaciones: “(i) como una pauta de comportamiento conforme a la cual deben obrar los individuos en ciertas situaciones, (ii) un criterio de interpretación en el análisis de acciones u omisiones de los particulares que vulneren o amenacen vulnerar derechos fundamentales y (iii) un límite a los derechos propios (Corte Constitucional S. T.-4., 2014).

En materia laboral, la Corte Constitucional ha acudido al principio de solidaridad para sustentar la existencia de una estabilidad laboral reforzada a favor de las personas que, a raíz de una disminución en sus condiciones físicas, no pueden trabajar en igualdad de condiciones, $y$ en el beneficio de la labor contratada; sin embargo, además de los problemas de esta fundamentación, a estos argumentos se les contraponen unos mejores, que hacen pensar que los principales obligados podrían ser, en ciertos casos, el mismo trabajador y el Estado. Los problemas de la fundamentación de los argumentos de la Corte se encuentran en que la solidaridad (Duguit, 1920, pág. 87) es un concepto general que cubre a todos los miembros de la sociedad, el cual entra a obrar, especialmente, por vía de la representación del cuerpo social encarnado en el Estado, más que en una persona específica. El principio de solidaridad, por lo general, no vincula a personas determinadas, pues se establece como un elemento general que cubre a todos los miembros de la comunidad. No dice nada acerca de que sea el empleador quien debe asumir la carga, el hecho de que se situé en cabeza de una persona determinada, si esta no tuvo una responsabilidad directa en la situación, constituye un trato desproporcionado. La medida de mantener el vínculo laboral con un trabajador que no puede laborar adecuadamente es una obligación desproporcionada a título del empleador en la mayoría de las ocasiones en las que no tuvo más responsabilidad que la de cualquier miembro de la sociedad (Suárez Manrique, W., \& de León Vargas, G., 2019, pág. 10). 


\section{El empleador hipotético y la regla de responsabilidad; el trabajador perfectible, un destinatario encubierto}

En este apartado se desea exponer una solución inspirada en la dignidad humana (González, 2004, pág. 47) para el problema de “los sujetos” en la estabilidad laboral reforzada. Esta solución parte de tres aclaraciones. La primera se refiere a que la solución que se plantea pretende ser lo más simple posible. La segunda respecta a que la protección a los trabajadores en situación de discapacidad debe otorgarse con extrema prudencia. La tercera alude a que la propuesta que se plantee pretende ser igualitarista (Dworkin, 2003, pág. 178), desde la perspectiva que trate con consideración y respeto a los involucrados en el caso.

Uno de los temas que, en principio, se entendió de forma positiva en el marco de la doctrina de la Corte Constitucional fue la ampliación de la protección de personas discapacitadas a personas en estado de vulnerabilidad, se creyó que extender esta medida en alto grado ayudaba a que un mayor número de personas se beneficiaran por las medidas especiales de protección. Sin embargo, como ya se insinuó, tal solución debilita la medida de forma drástica. Entre mayor sea el número de personas beneficiadas menor será la posibilidad de la protección (Fernández, 2003, pág. 67).

En este punto las preguntas centrales por responder son las siguientes: ¿quiénes deben ser los beneficiados de la protección?, ¿qué criterios se utilizan para identificarlos? Se hace necesaria, entonces, la deconstrucción de la figura (Ojeda, 2010, pág. 56). Los protegidos con la estabilidad en el empleo deben ser la menor cantidad de trabajadores posibles. Si se tiene en cuenta esta restricción, las consecuencias son positivas. En primer lugar, será más eficiente en la protección al estar, en pocas cabezas, la titularidad de tales derechos. Al ser un derecho de titularidad más concreta podrá delimitarse y exigirse de mejor forma; esto, en consecuencia, hará más real y efectiva su protección. Al ser más limitado el número de titulares se potenciará y perfilará de mejor forma la protección que los trabajadores requieren. Se evita, igualmente, que personas con leves afectaciones deseen o puedan aprovecharse de esta circunstancia, en perjuicio de quienes en realidad lo necesitan. Esto forzará y hará compatible la protección de los trabajadores con su libertad y con las obligación que tienen de ayudarse a sí mismos, por hacer que su vida valga la pena (Dworkin, 2003, pág. 87). Con estas premisas también se protege a los empleadores y a las personas que deban asumir las prestaciones en favor de los trabajadores. 
De lo que se ha dicho hasta el momento se ha sugerido que el número de titulares debe limitarse, pero no se ha expresado nada concreto en cuanto a las personas beneficiarias. Estos últimos no pueden ser los individuos con una grave afectación o con una limitación leve. Las personas que por alguna circunstancia (accidente o enfermedad, sin importar su origen) tengan una afectación grave y no puedan desempeñar sus labores, deberán evaluarse dentro del marco de referencia, pues la pensión de invalidez es para aquellos que sean declarados inválidos por enfermedad o por accidente, y que hayan cotizado cincuenta semanas dentro de los últimos tres años inmediatamente anteriores a la fecha de estructuración. Y puedan seguir desarrollando sus actividades laborales no son objeto de la estabilidad en el empleo. Pues, estas personas deben, de conformidad con la legislación existente, ser pensionadas, Según el Artículo 1 de la Ley 860 de 2003, que modificó el Artículo 39 de la Ley 100 de 1993. Quienes vean su capacidad laboral levemente disminuida tampoco deben ser objeto de esta protección, por cuanto serían la gran mayoría de asalariados, inclusive, por causa del mero paso del tiempo o por cualquier problema de distinta índole que les afecte. Todos los trabajadores padecen de ciertas limitaciones intelectuales, sociales, culturales, que les impiden desarrollar de forma adecuada sus labores. El modelo de trabajador no es el de la persona con capacidades idóneas, sino el del ser humano, demasiado humano, con las limitaciones diversas que todos ostentamos. Así las cosas, no se puede otorgar ni una híper protección ni una infra protección a los trabajadores.

El criterio de la Corte, además de general, sigue la idea trazada desde una perspectiva que puede catalogarse como interna y subjetiva. Es interna en el sentido de que el acento recae sobre las circunstancias del trabajador, es decir, que se trata de revisar una situación particular; y es subjetiva, porque los elementos para catalogar dicha situación son muy complejos y presentan un amplio margen discrecional. En la sentencia T-483 de 2014, la Corte Constitucional ratificó su posición respecto al reconocimiento de la pensión de invalidez a las personas que la ley considera en dicho estado. A tenor literal instituyó:

En aquellos casos en los que se deba establecer la fecha de estructuración de la pérdida de la capacidad laboral de una persona que sufra una enfermedad congénita, que tal padecimiento no le haya impedido ejercer actividades laborales remuneradas durante ciertos períodos de tiempo, la entidad encargada de realizar el dictamen de pérdida de la capacidad laboral deberá tener en cuenta que la fecha de estructuración corresponde 
a aquella en que el afiliado ve disminuidas sus destrezas físicas y mentales, en forma permanente y definitiva, en tal grado, que le impide desarrollar cualquier actividad económicamente productiva. Pues de lo contrario, se estarían poniendo en riesgo los derechos fundamentales al mínimo vital y a la seguridad social de sujetos en condiciones de debilidad manifiesta (Corte Constitucional S. T.-4., 2014) .

En su lugar, se propone un criterio externo que tiene por finalidad buscar mayor objetividad. Como sustituto del "trabajador vulnerable" emerge el "empleador hipotético” (pues se busca proteger al trabajador no de sí mismo sino de circunstancias externas). Entre este espectro se han de escoger las personas que no pueden desempeñar sus labores de forma tal, que serían contratadas para desarrollar el (su) empleo por un empleador hipotético. Si es posible que el trabajador continúe ejecutando sus labores, como el trabajador imperfecto que es, en esa empresa o en cualquier otra, no es objeto de protección. Luego, las personas objeto de protección son aquellas que no serían contratadas por un empleador hipotético, o si lo fueren, sería en condiciones laborales menos ventajosas que las que ya tienen.

Para proteger la situación de debilidad de un trabajador, el parámetro para medir la protección que debe otorgársele no puede ser la situación del empleado en cuanto tal, sino su concepción externa por parte de un posible empleador. Si la situación se revisa desde la óptica del trabajador, de las afectaciones a sus cualidades intelectuales, físicas y sociales, es muy posible que la percepción que se tiene sea ampliada. Esta concepción del trabajador vulnerable enfoca el criterio de revisión desde una perspectiva individualista. No quiere decirse que la forma en la que se sienta un trabajador no sea importante, o que su visión sea errada sobre las situaciones que lo afectan; ese trata de proponer una perspectiva imparcial. Tampoco se pretende restar importancia a los dictámenes periciales que los expertos galenos realizan sobre la disminución de la capacidad laboral de los trabajadores, no es que se piense que los resultados por ellos exhibidos carezcan de sentido. Desea, especialmente, resaltarse la visión del empleador hipotético en estos eventos.

Así las cosas, se debe proteger un número reducido de trabajadores, aquellos que no serían contratados por un empleador hipotético. El cambio dado de revisión de aspectos externos y objetivos sobre aspectos internos y subjetivos, presenta igualmente ciertos problemas difíciles de dilucidar, empero, ello no implica que no se haya dado un adelanto en la revisión de estos temas. Es importante tener en cuenta que existen situaciones que 
deben ser resueltas más en favor de la certeza de su cumplimiento que en las expectativas irrealizables.

Ahora bien, en cuanto al destinatario, se debe cambiar la visión de la Corte Constitucional, no debe ser exclusivamente el empleador el principal responsable de la protección del empleo bajo la figura de la estabilidad laboral reforzada. Debe verse una protección integral que repercuta en la corresponsabilidad social (Suárez Manrique, W., \& de León Vargas, G., 2019, pág. 10) y la finalidad de la figura.

Existen, con base en una visión comprensiva y móvil de las relaciones jurídicas y los derechos, tres destinatarios de la protección en el empleo: el trabajador, el empleador y el Estado. El primer responsable, aunque parecería paradójico y anti técnico, en la búsqueda de soluciones para la protección al empleo, es el propio trabajador. Y no solo se trata de un deber moral, sino de uno jurídico, en la medida en que su omisión implica consecuencias en este sentido. No debe concebirse tal situación como alarmante; el derecho está lleno de estas circunstancias, las cuales han pasado arropadas bajo figuras como el principio de buena fe (Bernal, 2006, pág. 45), la mala fe, la solidaridad y la autoayuda (Dworkin, 2003, pág. 120). Desde un enfoque constitucional, jurisprudencial y legal, puede fundamentarse esta perspectiva en el principio de buena fe, las responsabilidades derivadas del ejercicio de los derechos, el deber de respetar los derechos ajenos (Suàrez, 2012, pág. 18) y la ejecución de buena fe del contrato.

Constitucionalmente, la obligación de actuar de buena fe se establece como un presupuesto de todas las actuaciones. La CP instituye, en el Artículo 83, que "las actuaciones de los particulares y de las autoridades públicas deberán ceñirse a los postulados de la buena fe”. Además del amplio contenido que ostenta esta institución jurídica, la forma estructural y operativa de la buena fe ha venido consolidando un papel más fuerte e importante en la regulación de las relaciones jurídicas. Esto ha llevado a que se le otorguen funciones integradoras y de irradiación en las relaciones entre los particulares. Sobre esta concepción la Corte Constitucional, en la Sentencia T-1194 de 2008, ha establecido que

la buena fe ha pasado de ser un principio general de derecho para transformarse en un postulado constitucional, su aplicación y proyección ha adquirido nuevas implicaciones, en cuanto a su función integradora del ordenamiento y reguladora de las relaciones entre los particulares y entre 
estos y el Estado, y en tanto postulado constitucional, irradia las relaciones jurídicas entre particulares, y por ello la ley también pueda establecer, en casos específicos, esta presunción en las relaciones que entre ellos se desarrollen (Corte Constitucional e. 1.-1., 2008).

Por su parte, en el Artículo 95 de la Constitución Política de Colombia, se establecen directamente responsabilidades y deberes constitucionales como presupuestos y límites para el ejercicio de los derechos. Se instituyen como presupuestos por cuanto resultan ser condiciones para el ejercicio adecuado de los derechos y límites en cuanto en la medida en que son puntos infranqueables para la realización de los mismos. "El ejercicio de los derechos y libertades reconocidos en esta Constitución implica responsabilidades (Constituciòn, 1991)". El mismo precepto, más adelante, señala como deber de las personas "[r]espetar los derechos ajenos y no abusar de los propios”. La Corte Constitucional, en la Sentencia C-033 de 1993, preceptuó:

La libertad de información se constituye en un derecho fundamental cuyo ejercicio goza de protección jurídica y a la vez implica obligaciones y responsabilidades. Es pues un derecho-deber, esto es, un derecho no absoluto, sino que tiene una carga que condiciona su realización.

En la Sentencia T-125 de 1994, la Corte consideró lo siguiente:

Los deberes constitucionales son aquellas conductas o comportamientos de carácter público, exigibles por la ley a la persona o al ciudadano, que imponen prestaciones físicas o económicas y que afectan, en consecuencia, la esfera de su libertad personal.

Excepcionalmente, los deberes constitucionales son exigibles directamente. Ello sucede, entre otros eventos, cuando su incumplimiento, por un particular, vulnera o amenaza derechos fundamentales de otra persona, lo que exige la intervención oportuna de los jueces constitucionales para impedir la consumación de un perjuicio irremediable (Corte Constitucional S. T.-1., 1994).

\section{El Artículo 55 del Código Sustantivo del Trabajo establece que}

El contrato de trabajo, como todos los contratos, debe ejecutarse de buena fe y, por consiguiente, obliga no solo a lo que en él se expresa, sino a todas las cosas que emanan precisamente de la naturaleza de la relación jurídica o que por la ley pertenecen a ella. 
El postulado constitucional de la buena fe, los deberes y responsabilidades constitucionales, se encuentran materializados en esta disposición legislativa, la cual debe ser interpretada de conformidad con las pautas de la Carta. Por lo cual, su contendido, alcance, límites y análisis estructural se condicionan por la doctrina constitucional.

En la Sentencia C-299 de 1998, la Corte instó:

El contrato de trabajo presupone, el cumplimiento recíproco de las obligaciones correspondientes, al respeto mutuo entre el empleador y el trabajador y entre este y los demás compañeros de trabajo, al igual que con los representantes del empleador con el fin de lograr que el desarrollo y ejecución de la relación contractual se realicen en forma pacífica y armónica, y primen en ella la confianza, la lealtad y la solidaridad. Tanto los trabajadores como los patronos deben observar siempre, en sus relaciones laborales, comportamientos en los que prime el respeto mutuo. Igualmente, los trabajadores están obligados a respetar a sus superiores y sus compañeros, de manera que se desarrollen y ejecuten las labores contratadas en armonía y paz, de lo contrario, no solo se verían afectados los intereses de la empresa sino todo el personal que allí labora.

En la Sentencia T-125 de 1994, la Corte expuso un planteamiento que puede condensar los argumentos previos:

Los particulares deben conducirse en todas sus actuaciones según el principio de la buena fe. En el plano negocial (SIC), las partes deben comportarse con lealtad, lo que se traduce, en términos prácticos, en el respeto de los derechos ajenos y en el no abuso de los propios. El abuso de las posiciones dominantes rompe el equilibro contractual.

Así las cosas, los argumentos emitidos por la Corte Constitucional en torno al destinatario de la estabilidad laboral reforzada parecen, de cierta forma, pasar por alto las responsabilidades y deberes constitucional y legalmente establecidos. Tales argumentos se sustentan en una visión unidireccional de las relaciones jurídicas, sin revisar de forma integrada la manera como se condicionan los derechos y deberes.

El trabajador ostenta una responsabilidad meridiana en la suerte de sus infortunios laborales; que sea responsable no quiere decir que siempre sea quien tiene que asumir las cargas. La máxima utilizada por la Corte en la protección 
de los trabajadores, que puede llamarse la máxima de la no-responsabilidad, se traduce en que los trabajadores no tienen ningún compromiso en las situaciones desfavorables que les acaezcan, por lo que es el empleador quien debe de asumir y hacerse cargo de las afectaciones que sufran.

La solución correcta, de conformidad con el respeto a los derechos fundamentales del empleador, y en especial con los deberes y responsabilidades constitucionales y legales, establecidos en los artículos 83 y 95 de la CP, y 55 del CST, es la variación de la máxima de la no responsabilidad por la de la responsabilidad, en la que la conducta de los trabajadores se deba ponderar adecuadamente. De esta se derivan dos obligaciones generales: una preventiva y otra restaurativa. La primera es una obligación general que tienen todas las personas por su condición de humanos y en el desarrollo de sus derechos fundamentales o legales, derivados de la dignidad humana (Lobato, 1997), y del respeto (Dworkin, 2003, pág. 78), la cual, en el contexto de estudio, se traduce en el deber que tiene el trabajador de obrar con responsabilidad y diligencia en el adelanto de sus actividades laborales y personales.

La concepción preventiva del Derecho (Suàrez, 2012), conlleva a que el trabajador deba minimizar en lo posible la ocurrencia de accidentes y situaciones que le puedan llevar a mermar su capacidad laboral. El Artículo 58 del CST, en su numeral 8, estipula como obligación del trabajador "observar con suma diligencia y cuidado las instrucciones y órdenes preventivas de accidentes o de enfermedades profesionales”. Este precepto específica y fundamenta la obligación referida. El Artículo 22 del Decreto 1295 de 1994, establece como deberes de los trabajadores "procurar el cuidado integral de su salud”; "cumplir las normas, reglamentos e instrucciones de los programas de salud ocupacional de la empresa”, y "participar en la prevención de los riesgos profesionales”.

No se hace necesario el establecimiento de reglas ulteriores si se tratan de corregir las conductas que pueden llevar a situaciones desfavorables. Resulta ineficiente (Posner, 2011, pág. 35) la solución dada por la Corte cuando su resultado es llegar a situaciones desventajosas para los involucrados, tanto para el trabajador como para el empleador. Luego, una forma simple de prevenir las aporías de las reglas dadas por la Corte resulta ser la de buscar la reducción de los costos de las discapacidades ocasionadas.

La segunda obligación, de carácter restaurativo, consiste en escudriñar formas de contribuir en la superación de las situaciones que le han acaecido, 
en búsqueda de una autorrealización y un ejercicio adecuado de su plan de vida, acorde con las exigencias de la libertad, establecida en el Artículo 16, y la igualdad, presente en el Artículo 13 de la CP. Así pues, la inestabilidad del derecho y su visión atómica (Suárez Manrique, W., \& de León Vargas, G., 2019, pág. 4), permiten que las obligaciones jurídicas sobre un mismo objeto se entrecrucen y se definan por criterios de prioridad. En este caso se trata de una obligación que tendría el trabajador consigo mismo y con la sociedad.

Esta obligación, de manera legal, puede fundarse en la Resolución 1016 de 1989, en el Decreto 2177 de 1989, y en artículos los 4 y 8 de la Ley 776 de 2002, regulaciones que enmarcan los procesos de rehabilitación integral de los trabajadores. El empleado cumple su deber prestando todo su esfuerzo, colaboracióny autoayuda para tratar de incorporarse y recuperarse de las afrentas que ha sufrido, o buscando la adaptación de sus capacidades para adelantar sus labores de manera adecuada. Sería inocuo el proceso de rehabilitación si no se contara con la responsabilidad del trabajador. Este es quien ostenta la obligación de respeto hacia sí mismo y hacia la sociedad, luego, debe suministrar todas sus capacidades para su recuperación en aras a su reinserción adecuada. Si el trabajador no cumple con sus obligaciones, y caso contrario, quiere hacer más gravosa su situación a efectos de forzar una mayor protección del ordenamiento jurídico y aprovecharse de las reglamentaciones legales y judiciales existentes, no merece las prestaciones establecidas por la ley.

\section{Conclusiones}

En el presente trabajo se concluyen dos ideas: por un lado, se exhibe el criterio del empleador hipotético como sustituto del criterio del trabajador vulnerable, y, por otro, se expone la regla de la responsabilidad como sustituta de la regla de la no responsabilidad.

Así las cosas, el criterio que se plantea como sustituto del trabajador vulnerable es el del empleador hipotético. Luego, las personas objeto de protección son aquellas que no serían contratadas por un empleador hipotético, o si lo fueren, sería en condiciones laborales menos ventajosas que las que ya tienen. De esta forma se da un cambio hacia la revisión de aspectos externos y objetivos en detrimento de aspectos internos y subjetivos. 
Por otra parte, partiendo de la importancia de los deberes constitucionales y la corresponsabilidad social, se plantea la regla de la responsabilidad en lo tocante a los destinatarios del derecho a la estabilidad laboral reforzada. Lo anterior, se funda en una visión comprensiva y móvil de las relaciones jurídicas y los derechos, de donde emergen tres destinatarios de la protección en el empleo: el trabajador, el empleador y el Estado. En consecuencia, de la máxima de la responsabilidad, en la que la conducta de los trabajadores se deba ponderar adecuadamente, derivan dos obligaciones generales: una preventiva y otra restaurativa.

\section{Referencias}

Baylos, A. (2009). El despido o la violencia del poder privado. Madrid: Trotta.

Bernal, C. (2005). El derecho de los derechos. Bogotá: Universidad Externado de Colombia.

Bernal, C. (2006). El neoconstitucionalismo a debate. Bogotá: Universidad Externado de Colombia.

Bernal, C. M. (2003). El principio de proporcionalidad y los derechos fundamentales. Madrid: Centro de Estudios Politicos y Constitucionales.

Burgoa, I. (1954). Las garantías individuales. México: Porrúa.

Calabresi, G. (1992). Reglas de propiedad, reglas de responsabilidad e inalienabilidad: un vistazo a La Catedral. . Lima: Themis.

Claro, L. (1978). Explicaciones de derecho civil chileno y comparado de las personas. Santiago de Chile: Jurídica de Chile.

Duguit, L. (1920). Las transformaciones generales del derecho privado desde el Código de Napoleón. Madrid: Libreria Española y Extranjera.

Dworkin, R. (2003). Virtud soberana. La teoría y la práctica de la igualdad. Barcelona: Paidós.

Fernández, F. (2003). Estudios constitucionales. México: Universidad Autónoma de México.

Forsthoff, E. (1986). Problemas constitucionales del Estado Social. El Estado Social. Madrid: Centro de Estudios Constitucionales.

González, J. (2004). Autonomía, dignidad y ciudadanía. Una teoría de los derechos humanos. Valencia: Tirant lo Blanch. 
Gorelli, J. (2010). El coste económico del despido o el precio de la arbitrariedad: un estudio sobre la eficacia del despido disciplinario ilícito. Sevilla: Consejo Andaluz de Relacionales Laborales.

Hernández, L. (1997). Poder de dirección del empleador. En: Instituciones del derecho del trabajo y de la seguridad social. México: Universidad Nacional Autónoma de México.

Lobato, A. (1997). Dignidad y aventura humana. Salamanca: San Estéban-Edibesa.

Ojeda, A. (2010). La deconstrucción del derecho del trabajo. Madrid: La Ley.

Paine, T. (1984). Los derechos del hombre. Madrid: Alianza.

Petev, V. (1996). Metodología y ciencia jurídica en el umbral del siglo XXI. Bogotá: Universidad Externado de Colombia.

Posner, R. (2011). Cómo deciden los jueces. Barcelona: Marcial Pons.

Suárez Manrique, W., \& de León Vargas, G. (2019). El mito de la estabilidad constitucional. Vía luris, 26, 1-32.

Suárez, W. (2012). El principio de proporcionalidad sistémico. Bucaramanga: Universidad Santo Tomás.

Ugarte, J. (2011). Privacidad, trabajo y derechos fundamentales. Santiago de Chile: Estudios Constitucionales.

Vigo, R. (2003). El iusnaturalismo actual. México: Biblioteca de ética, filosofía del derecho y política

Vila, I. (2011). Fundamentos del derecho constitucional contemporáneo. Bogotá: Legis. 